Endocrinol Metab Clin North Am. 2012 September ; 41(3): 629-641. doi:10.1016/j.ecl.2012.05.001.

\title{
Male Osteoporosis
}

\author{
Matthew T. Drake and Sundeep Khosla \\ College of Medicine, Mayo Clinic, Rochester, MN, USA
}

\section{Synopsis}

Osteoporosis is now recognized as a major threat to health in aging men. Morbidity and mortality, particularly following hip fracture, are substantial. Whereas trabecular bone loss starts in early adulthood, loss of cortical bone only appears to occur from mid-life onwards. Declining bioavailable estradiol levels play an integral role in male age-associated bone loss. Both pharmacologic and supportive care interventions are important for optimal care in men at increased fracture risk.

\section{Keywords}

osteoporosis; men; fracture; epidemiology; DXA; QCT; sex steroids

\section{Introduction}

Osteoporosis is defined as an asymptomatic bone disease marked by low bone mass and skeletal microarchitectural deterioration resulting in increased fracture risk ${ }^{1}$. Although osteoporosis has been widely recognized by medical professionals and the public as a significant health issue in aging women, it is now also increasingly viewed as a major health threat to the aging male population in terms of morbidity, mortality, and health care resource expenditure.

\section{Male Fracture Epidemiology}

Despite not undergoing a menopausal transition as do women, men sustain bone loss of approximately $0.5-1 \%$ per year beginning by the sixth decade ${ }^{2}$. Current estimates are that approximately $20 \%$ of Americans with osteopenia or osteoporosis are male, and that one in eight men over aged 50 years will incur an osteoporotic-type fracture during his lifetime, with roughly $30 \%$ of hip fractures occurring in men $^{3}$. Fractures at both the hip and vertebrae have been shown to increase morbidity and mortality in $\mathrm{men}^{4,5}$, with hip fractures in men associated with an approximately $2-3$ fold increased mortality risk relative to women ${ }^{6}$.

Fracture incidence in males has two peaks: one around adolescence and a second, sustained peak which occurs at advanced age. Prior to age 50 years, males experience more fractures than females, likely due primarily to increased rates of high energy trauma (such as athletic

(C) 2012 Elsevier Inc. All rights reserved.

Correspondence: Matthew T. Drake, M.D., Ph.D., Endocrine Research Unit, Guggenheim 7-11, Mayo Clinic, 200 First Street SW, Rochester, MN 55905, USA, drake.matthew@mayo.edu; Phone: (507) 284-2463; Fax: (507) 284-5745.

Co-author: khosla.sundeep@mayo.edu

Publisher's Disclaimer: This is a PDF file of an unedited manuscript that has been accepted for publication. As a service to our customers we are providing this early version of the manuscript. The manuscript will undergo copyediting, typesetting, and review of the resulting proof before it is published in its final citable form. Please note that during the production process errors may be discovered which could affect the content, and all legal disclaimers that apply to the journal pertain. 
and work-place related injuries) in younger men relative to women ${ }^{7}$. Men subsequently experience an exponential rise in fractures beginning after about age 75 , although the absolute fracture incidence in older men remains less than in age-matched women.

Using data from the year 2000, it has been estimated that approximately 9.0 million new osteoporotic fractures occur yearly, and that roughly $39 \%$ of these occur in men ${ }^{5}$. In the General Practice Research Database in the United Kingdom followed from 1988-1998, 103,052 men among the 5 million adults followed sustained a fracture over 10.4 million person years of follow-up 7 . In men, aging was associated with increased risk for fracture of the vertebrae, femur, forearm, humerus, clavicle, scapula, pelvis, and ribs; thus, these fracture types were considered more likely to be associated with osteoporosis. Similar to these findings, other studies of aged men have also shown increased rates of non-vertebral fractures of the proximal femur, humerus, and forearm ${ }^{8,9}$. Taken together, these findings suggest that osteoporotic fractures in men primarily involve the hip, vertebrae, humerus, and forearm, although fractures at other sites including the ribs, pelvis, and clavicle are also associated with male aging.

\section{Hip fractures}

In men, hip fractures are associated with the greatest morbidity and mortality. While current evidence suggests that hip fracture rates in Western populations appear to have stabilized over the past two decades, hip fracture rates may be rising in other parts of the world, including $\mathrm{Asia}^{10}$. Indeed, current estimates are that the number of men worldwide with hip fracture will be between 1.8 and 6.8 million by $2050^{3,11}$. Although absolute incidence rates vary geographically, overall incidence rates worldwide have been found to increase exponentially beginning at roughly age $75^{12}$. Mortality is substantially higher in men compared to women following hip fracture. Men are nearly twice as likely to die during their immediate post-fracture hospitalization ${ }^{13}$, and roughly one-third of men die within the first year following fracture ${ }^{14,15}$. Morbidity is also increased in men compared to women following hip fracture; nearly half of men require skilled institutionalized care following hip fracture $^{16}$, and men are far less likely when compared to women to return to full independence at one year following hip fracture ${ }^{17}$. Further, although it is well documented that both men and women continue to be undertreated for their osteoporosis following hip fracture $^{18}$, men appear to be disproportionally more likely to be undertreated ${ }^{19}$.

\section{Vertebral fractures}

Like hip fractures, vertebral fracture incidence in men increases with aging. As shown in the European Prospective Osteoporosis Study (EPOS) of 3174 men (mean age 63.1 years) who had spinal radiographs performed at a mean of 3.8 years following a baseline film, the agestandardized incidence of morphometric fractures was 5.7/1000 person years, a rate slightly lower than the $10.7 / 1000$ person years determined in women ${ }^{20}$. As expected, incidence in both sexes increased markedly with progressive age. Similar trends have been demonstrated in numerous other studies performed both in the United States and Europe ${ }^{21-24}$, with small differences in incidence/prevalence rates between the studies likely reflecting subject inclusion criteria, study methodologies, as well as geographic variation. Importantly, vertebral fractures increase the likelihood of subsequent fractures in both sexes ${ }^{25}$, 26, have been shown to be a positive predictor of age-adjusted mortality in $\mathrm{men}^{26}$, and are associated with multiple indices of poorer life quality ${ }^{27}$.

Although fracture data in men at sites other than the spine and hip are more limited, there is now good evidence that low trauma fractures of the upper arm (forearm and humerus) and ankle are associated with an increased risk for future fractures in men $^{28}$. 


\section{Prevalence of Low Bone Mass in Men}

As defined by the World Health Organization, osteopenia is a bone mineral density (BMD) measured by dual-energy X-ray absorptiometry (DXA) between 1.0 and 2.5 standard deviations (SD) below the young adult (aged 20-29) normative reference mean, with osteoporosis defined as a BMD value of less than $2.5 \mathrm{SD}$ below the mean value. Using femoral BMD data from the Third National Health and Nutrition Survey (NHANES III) and a BMD normative reference range derived from non-Hispanic whites, Looker and colleagues found that substantial numbers of men had low bone mass. Using a male reference range, 3-6\% of men had osteoporosis and $28-47 \%$ osteopenia; using a female reference mean, $1-4 \%$ of men had osteoporosis, while $15-33 \%$ were osteopenic ${ }^{29}$. By comparison, Melton and colleagues used a population-based sample of Rochester, Minnesota men to determine a prevalence estimate of $19 \%$ for osteoporosis in men aged 50 and older when using a male reference range, but only $3 \%$ when using a female reference range $^{30}$. There remains some debate as to whether sex-specific reference ranges may be more appropriate than a single female-based reference range for describing low bone mass in men ${ }^{31,32}$, although it is clear that the use of a male-specific database identifies more men as having diminished bone mass (osteopenia and osteoporosis). Estimates of low bone mass from DXA data in men other than non-Hispanic whites is more limited, but suggests that non-Hispanic white men have the highest prevalence of osteopenia/osteoporosis, followed by Mexican-American men and non-Hispanic black men $^{29}$, results which are consistent with hip fracture incidence among males of different ethnic backgrounds ${ }^{33}$.

\section{Risk Factors for Bone Loss in Men}

Due to the combination of an improved male longevity, the significant morbidity associated with fractures in aged males, and the broad availability of pharmacologic agents which documented efficacy for reducing fracture risk, it is increasingly important to identify men at increased fracture risk for low BMD-associated fractures. There are many reasons why male bone loss occurs, which can broadly be grouped into primary (age-associated and idiopathic) and secondary (all other) causes (Box 1). In individual men, bone loss may result from a single cause, or be due to a combination of multiple factors. A more thorough review of risk factors associated with bone loss is men is beyond the scope of this review, but has been reviewed recently ${ }^{34}$.

\section{Box 1}

\section{Primary and secondary causes of male osteoporosis}

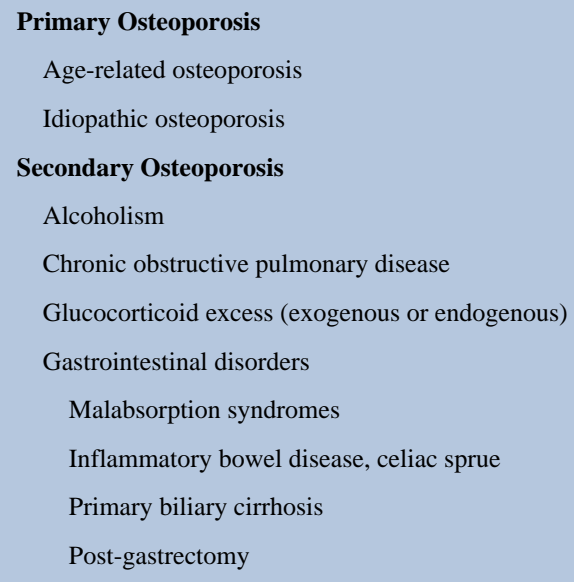




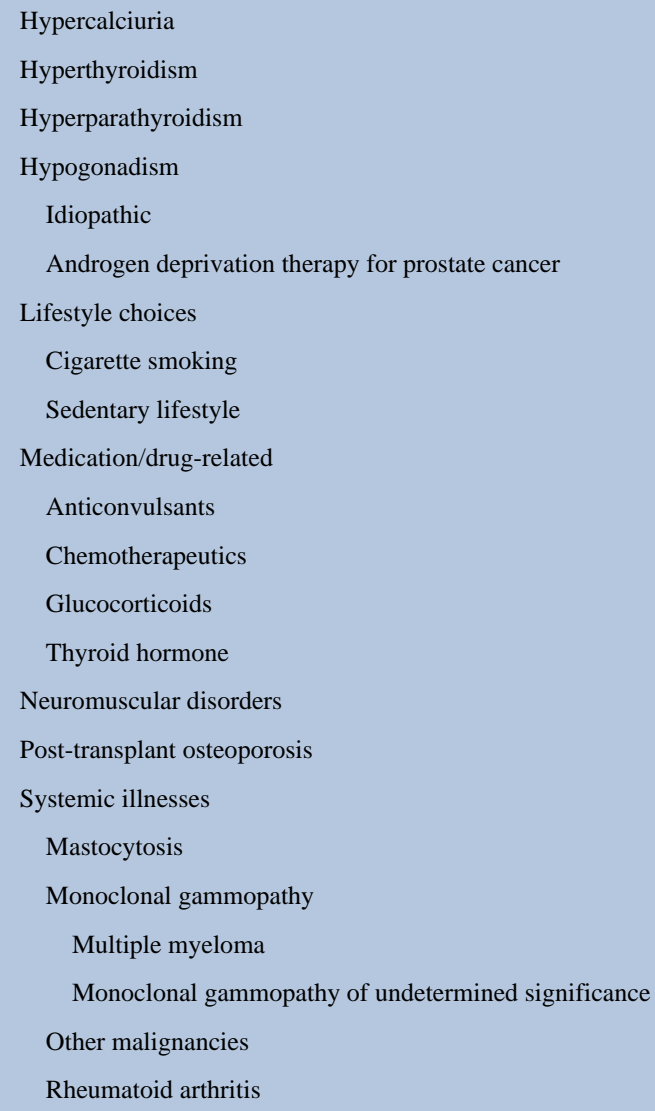

Adapted from Khosla et al. (2008) Endocrine Reviews 29:441-464 with permission from the Endocrine Society.

\section{Etiology of Male Bone Loss}

Although DXA is the best-established clinical method for assessing bone loss, DXA only allows for assessment of 'areal' BMD and therefore lacks the ability to distinguish between cortical and trabecular bone components. Recent advances in bone imaging, however, have allowed for significantly enhancement in our understanding of age-associated bone loss. Chief among these advances has been the application of quantitative computed tomography (QCT) to both central and peripheral skeletal sites, technology which allows for true assessments of 'volumetric' BMD (vBMD) and bone microstructural changes either crosssectionally or longitudinally. Accordingly, Riggs and colleagues recently assessed bone geometry and $\mathrm{vBMD}$ by QCT at the lumbar spine and femoral neck, and peripheral QCT at the distal radius and tibia in a population-based sample of 323 men aged 20-97 years from Rochester, Minnesota ${ }^{35}$. As seen in Figure 1, substantial (approximately 46\%) nearly linear loss of lumbar spine (composed primarily of trabecular bone) vBMD occurred across the entire adult male lifespan. In contrast, cortical vBMD as assessed at the radius remained essentially stable until approximately the sixth decade in men, thereafter decreasing nearly linearly by approximately $18 \%$.

In addition to changes in vBMD, changes in bone geometry also occur with aging. As again demonstrated by Riggs et al., aging in males was associated with increases in bone cross- 
sectional area at the femoral neck due to progressive periosteal apposition with concomitant increases in endocortical resorption, ultimately resulting in a slight decline in cortical area and thickness. Importantly, however, this net outward cortical displacement increases resistance to bending stresses, thereby providing a partial biomechanical adaptation to limit the overall loss of bone strength due to the decreases in cortical area and thickness ${ }^{36}$.

Additional studies from the Osteoporotic Fractures in Men (MrOs) cohort examining changes in vBMD and bone dimensions at the femoral neck and shaft by QCT in a cohort of 3358 men aged 65-100 demonstrated that at the femoral neck, trabecular vBMD was $22.1 \%$ lower in men aged > 85 years compared to men aged 65-69 years, but that cortical vBMD was similar between the two groups ${ }^{37}$. Confirming the results described by Riggs et al, increased endocortical resorption and periosteal apposition with resultant cortical thinning but outward cortical displacement was also observed at the femoral neck in the older versus younger aged men. At the femoral shaft by comparison, both the cross-sectional and medullary areas were increased ( $9 \%$ and $22 \%$, respectively) in the older versus younger men, with $\%$ shaft cortical bone and shaft cortical vBMD both $4 \%$ lower in the older men.

Together, these studies demonstrate that whereas trabecular bone loss in men (and indeed, in women) begins in early adulthood, cortical bone loss only appears to begin with mid-life. Further, although an increase in periosteal apposition leads to an increase in bone cross sectional area with aging, a simultaneous increase in endocortical resorption ultimately results in the overall decline in cortical area.

\section{Male Bone Microstructural Changes with Aging}

The more recent development of high-resolution peripheral QCT (HRpQCT), which can be used to image peripheral skeletal sites (wrist and tibia) at much higher resolution than standard QCT, has allowed for even more accurate non-invasive assessment of bone microstructure. In a population-based cross-sectional study of 278 Rochester, Minnesota men aged 21-97 years highly characteristic of the United States white population, Khosla and colleagues used HRpQCT to examine bone microstructure at the ultradistal radius ${ }^{38}$. Relative to young aged-matched women aged 20-29 years, men had markedly greater bone volume (BV)/tissue volume (TV) and trabecular thickness (26\% and 28\%, respectively), but little difference in trabecular number or separation. Interestingly, while cross-sectional decreases in trabecular BV/TV were approximately $26 \%$ in both sexes between ages 20-90 years, the structural basis for these declines was fundamentally different. Whereas women lost trabeculae and increased trabecular separation over the lifespan, men primarily sustained trabecular thinning without trabecular loss. Importantly, these data are in accordance with previous histomorphometric studies of cadaveric transiliac bone biopsies obtained over approximately the same age range of 20-90 years, suggesting that the changes determined by HRpQCT may be similar at other skeletal sites. If so, this may partially explain the reduced fracture incidence seen in men compared to women with aging, as decreases in trabecular number are anticipated to have a greater impact on bone strength relative to decreases in trabecular thickness ${ }^{39}$.

\section{The Role of Sex Steroids in Male Osteoporosis}

Although the role of declining sex steroid levels in bone loss is best recognized in women, marked changes in sex steroid levels also occur over the male lifespan. Unlike women in whom menopausal-associated ovarian failure is the primary cause, declining sex-steroid levels in men are principally due to a greater than two-fold age-associated increase in sex hormone binding globulin (SHBG) levels ${ }^{40}$. This SHBG increase limits the biologically available [free (1-3\%) and albumin-associated 35-55\%] sex steroids, leading to declines in 
bioavailable testosterone and estrogen levels of $64 \%$ and $47 \%$, respectively, over the male lifespan ${ }^{40}$.

While testosterone is the predominant male sex steroid, both cross-sectional ${ }^{41-46}$ and longitudinal ${ }^{47}$ evidence indicates that levels of bioavailable estradiol (E2) rather than testosterone are better correlated with male BMD. In support of this, a longitudinal study which evaluated sex steroid levels in a younger male cohort (22-39 years; an age range in the final stages of skeletal maturation) versus an older male cohort (60-90 years; an age range in which age-related bone loss occurs) over a 4-yr interval found that while distal forearm BMD (primarily reflecting cortical bone compartment changes) in the younger cohort increased approximately 0.42-0.43\%/year, distal forearm BMD in the older men declined by $0.49-0.66 \% /$ year $^{47}$. Importantly, the increased BMD in younger men and the decreased BMD in older men were more closely associated with bioavailable E2 levels than with testosterone levels. Further, in older men there appeared to be a 'threshold' bioavailable E2 level of $\sim 40 \mathrm{pM}(11 \mathrm{pg} / \mathrm{mL})$, below which bone loss rates appeared to increase. Further vBMD analyses showed that this bioavailable E2 threshold correlated better with cortical than trabecular sites ${ }^{48}$. Above this threshold, however, there was no firm relationship seen between bone loss rates and bioavailable E2 levels. Additional work has supported this threshold effect for bioavailable and total E2 ${ }^{49}$, although the absolute threshold determined by other investigators has varied slightly depending on whether E2 levels were determined by immunoassay (approximately $20-25 \mathrm{pg} / \mathrm{mL}$ ) or mass spectroscopy $(16 \mathrm{pg} / \mathrm{mL})^{50,51}$.

While correlative, the above findings provide no direct evidence of a causal role for estrogen in male bone health with aging. In order to directly assess the role of sex steroids [estrogen (E) and testosterone (T)] on skeletal health in aging men, Khosla and colleagues undertook a direct interventional study in which they suppressed endogenous testosterone and estrogen production (by treatment with both a GnRH agonist and an aromatase inhibitor) while simultaneously providing physiologic replacement levels of estrogen and testosterone by topical patch placement ${ }^{52}$. Following determination of baseline bone turnover markers while on the above endogenous suppression/physiologic replacement regime, subjects were randomized into one of four groups: group A $(-\mathrm{T},-\mathrm{E})$ discontinued both patches; group B $(-\mathrm{T},+\mathrm{E})$ continued only the estrogen patch; group $\mathrm{C}(+\mathrm{T},-\mathrm{E})$ continued only the testosterone patch; and group D $(+\mathrm{T},+\mathrm{E})$ continued both patches. Accordingly, the study design permitted determination of bone metabolism changes due to either estrogen or testosterone, since endogenous sex steroid production was suppressed throughout the entire study.

As seen in Figure 2, complete absence of both T and E (group A) resulted in significant increases in bone resorption which were completely prevented by treatment with both $\mathrm{T}$ and E (group D). Treatment with estrogen alone was almost completely able to prevent the increase in bone resorption (group B), however, whereas testosterone alone had only modest effects (group C). Comparatively, the significant decline in serum bone formation markers [osteocalcin and amino-terminal propeptide of type I collagen (P1NP)] that occurred with deficiency of both $\mathrm{T}$ and $\mathrm{E}$ (group A) were completely prevented by supplementation of both $\mathrm{T}$ and $\mathrm{E}$ (group $\mathrm{D}$ ); treatment with either $\mathrm{E}$ or $\mathrm{T}$ alone lead to only slight decreases in osteocalcin levels, whereas P1NP levels were maintained with E (group B) but not T (group C) treatment. Together, these results are consistent with a dominant role for estrogen as the major sex steroid regulating skeletal health in aged men.

With male aging, levels of bioavailable testosterone decline even more precipitously than those of bioavailable estrogen. Despite this decrease, however, the extent to which diminution of bioavailable testosterone levels impacts bone loss associated with male aging is less clear when compared to the role of declining bioavailable estrogen levels. As shown, testosterone imparts modest effects on bone resorption, and also affects bone formation 
(Figure 2). As recently demonstrated, increased femoral neck BMD occurred in aged men who received low-dose testosterone replacement for 2 year ${ }^{53}$ despite the absence of BMD increases at any other site examined (lumbar spine, total hip, or distal radius). Whether the effect of testosterone on femoral neck BMD in this study was direct, or rather the result of testosterone aromatization to estrogen, however, is unclear. Current evidence suggests that testosterone also likely plays a role in cortical appositional bone growth, although this has been most convincingly demonstrated in rodent studies ${ }^{54}$ and the extent to which testosterone has this function with aging in men is less clear.

Finally, it has been suggested that testosterone may play a more indirect role in male skeletal health with aging by allowing for relative maintenance of balance and muscle strength in men compared to women ${ }^{51}$. As such, the slightly lower fracture incidence in aged men relative to age-matched women may be partially reflective of the increased frequency of falling which occurs with aging in women relative to men 55,56 , with fractures after falls 2.2 fold higher in women than men ${ }^{57}$.

\section{Other Potential Causes of Male Bone Loss}

A variety of other factors have been postulated to play a role in age-associated male bone loss. These include an age-associated rise in parathyroid hormone levels ${ }^{58}$, decreases in growth hormone and circulating bioavailable insulin-like growth factor levels ${ }^{59}$, and inherent changes or loss of stem or osteoprogenitor cells ${ }^{60}$. Additionally, nutrition is also appears to be critical for optimal skeletal health, as failure to maintain adequate intake of vitamin $\mathrm{D}$, calcium, or protein have all been shown to lead to worsened bone health in men $^{12}$.

\section{Care for Male Patients with Bone Loss}

Reducing the substantial fracture risk which occurs with bone loss in men is now more widely recognized as an important goal of optimal patient care. Despite this recognition, however, the vast majority of studies using pharmacologic interventions have been performed in women; further, the comparatively fewer studies in men have typically assessed BMD changes as a surrogate for fracture risk. Nonetheless, current evidence suggests that the most commonly prescribed therapies (nitrogen-containing bisphosphonates and teriparatide) are as efficacious in men as they are in women.

\section{Bisphosphonates}

Alendronate ${ }^{61}$, risedronate ${ }^{62}$, ibandronate $^{63}$, and zoledronate ${ }^{64}$ have all been shown to increase BMD and reduce biochemical markers of bone turnover in men with low bone mass, with alendronate, risedronate, and zoledronate having received FDA approval for the treatment of osteoporosis in men. Importantly, BMD changes with bisphosphonate therapy appear to be equivalent in men with low free testosterone levels as in men with normal levels ${ }^{61}$, perhaps indicating why bisphosphonate therapy is effective in limiting bone loss in men receiving androgen deprivation therapy for prostate cancer. Bisphosphonates have also been shown to be effective for limiting bone loss in men receiving corticosteroid therapy 65 or in the setting of acute immobilization ${ }^{66}$.

\section{Teriparatide}

Once daily recombinant parathyroid hormone 1-34 increases BMD in men with low bone mass, and appears to reduce the risk for vertebral fractures ${ }^{67}$. As with bisphosphonates, results appear to be similar in magnitude to those seen in women, and teriparatide has received FDA approval for the treatment of osteoporosis in men. 


\section{Denosumab...}

The RANK ligand inhibitor was initially approved for the treatment of osteoporosis in women, and was more recently FDA-approved for the treatment of men with non-metastatic prostate cancer with osteopenia and a high risk of fracture receiving androgen-deprivation therapy.

A more complete review of additional potential pharmacologic agents for the management of male bone loss is beyond the scope of this review. Accordingly, the reader is referred to a recently published meta-analysis of the comparative effectiveness of currently available pharmacologic agents for reducing fracture risk in $\operatorname{men}^{68}$.

\section{Additional Supportive Care}

In addition to pharmacologic interventions, ensuring that men with low bone mass receive appropriate supportive care is essential for limiting fracture risk. Such care includes confirming that patients have adequate vitamin $\mathrm{D}$ and calcium intake both prior to, and while maintained, on therapy. In older community-dwelling men aged 65 years and older, moderate reductions in bone loss at the hip and spine, and reduced non-vertebral fracture incidence were seen in subjects receiving dietary vitamin $\mathrm{D}$ and calcium supplementation for three years compared to subjects who received placebo ${ }^{69}$. Notably, recommendations from the Institute of Medicine on dietary intakes of calcium and vitamin D have been recently published, with skeletal-related outcomes as the primary endpoint for most included studies ${ }^{70,71}$.

Finally, defining appropriate generalized exercise prescriptions in patients at increased fracture risk remains an important part of the care plan for most subjects, as increases in physical performance are expected to increase muscle mass and tone, thereby reduce frailty and decreasing fall risk. To date, however, studies which have attempted to examine this approach to exercise in at-risk patients have not used standardized methods. Due to the significant heterogeneity among studies which examined the role of exercise in fracture reduction, a recent review concluded that currently available data does not allow for proper quantitative assessment of risk associated with exercise in at-risk subjects ${ }^{34}$.

\section{Conclusions}

While much work over the preceding two decades has enlightened our understanding of male bone loss, significant challenges to providing optimal care to our male patients persist. Osteoporosis in men remains an under-recognized clinical problem which will continue to grow in importance with the aging of the population. Despite significant advances in our understanding of the epidemiology, risk factors, etiology, and therapeutic approaches to male osteoporosis, much work awaits if we are to limit future morbidity and mortality associated with bone loss in men.

\section{References}

1. Consensus development conference: diagnosis, prophylaxis, and treatment of osteoporosis. Am J Med. 1993; 94(6):646-650. [PubMed: 8506892]

2. Melton LJ 3rd, Khosla S, Achenbach SJ, et al. Effects of body size and skeletal site on the estimated prevalence of osteoporosis in women and men. Osteoporos Int. 2000; 11(11):977-983. [PubMed: 11193251]

3. Cooper C, Campion G, Melton LJ 3rd. Hip fractures in the elderly: a world-wide projection. Osteoporos Int. 1992; 2(6):285-289. [PubMed: 1421796] 
4. Johnell O, Kanis JA. An estimate of the worldwide prevalence, mortality and disability associated with hip fracture. Osteoporos Int. 2004; 15(11):897-902. [PubMed: 15490120]

5. Johnell O, Kanis JA. An estimate of the worldwide prevalence and disability associated with osteoporotic fractures. Osteoporos Int. 2006; 17(12):1726-1733. [PubMed: 16983459]

6. Center JR, Nguyen TV, Schneider D, et al. Mortality after all major types of osteoporotic fracture in men and women: an observational study. Lancet. 1999; 353(9156):878-882. [PubMed: 10093980]

7. van Staa TP, Dennison EM, Leufkens HG, et al. Epidemiology of fractures in England and Wales. Bone. 2001; 29(6):517-522. [PubMed: 11728921]

8. Schuit SC, van der Klift M, Weel AE, et al. Fracture incidence and association with bone mineral density in elderly men and women: the Rotterdam Study. Bone. 2004; 34(1):195-202. [PubMed: 14751578]

9. Jonsson BY, Siggeirsdottir K, Mogensen B, et al. Fracture rate in a population-based sample of men in Reykjavik. Acta Orthop Scand. 2004; 75(2):195-200. [PubMed: 15180235]

10. Cooper C, Cole ZA, Holroyd CR, et al. Secular trends in the incidence of hip and other osteoporotic fractures. Osteoporos Int. 2011; 22(5):1277-1288. [PubMed: 21461721]

11. Gullberg B, Johnell O, Kanis JA. World-wide projections for hip fracture. Osteoporos Int. 1997; 7(5):407-413. [PubMed: 9425497]

12. Khosla S, Amin S, Orwoll E. Osteoporosis in men. Endocr Rev. 2008; 29(4):441-464. [PubMed: 18451258]

13. Diamond TH, Thornley SW, Sekel R, et al. Hip fracture in elderly men: prognostic factors and outcomes. Med J Aust. 1997; 167(8):412-415. [PubMed: 9364155]

14. Kiebzak GM, Beinart GA, Perser K, et al. Undertreatment of osteoporosis in men with hip fracture. Arch Intern Med. 2002; 162(19):2217-2222. [PubMed: 12390065]

15. Bass E, French DD, Bradham DD, et al. Risk-adjusted mortality rates of elderly veterans with hip fractures. Ann Epidemiol. 2007; 17(7):514-519. [PubMed: 17420142]

16. Poor G, Atkinson EJ, O'Fallon WM, et al. Determinants of reduced survival following hip fractures in men. Clin Orthop Relat Res. 1995; (319):260-265. [PubMed: 7554638]

17. Schurch MA, Rizzoli R, Mermillod B, et al. A prospective study on socioeconomic aspects of fracture of the proximal femur. J Bone Miner Res. 1996; 11(12):1935-1942. [PubMed: 8970896]

18. Curtis JR, McClure LA, Delzell E, et al. Population-based fracture risk assessment and osteoporosis treatment disparities by race and gender. J Gen Intern Med. 2009; 24(8):956-962. [PubMed: 19551449]

19. Shibli-Rahhal A, Vaughan-Sarrazin MS, Richardson K, et al. Testing and treatment for osteoporosis following hip fracture in an integrated U.S. healthcare delivery system. Osteoporos Int. 2011; 22(12):2973-2980. [PubMed: 21271339]

20. Incidence of vertebral fracture in europe: results from the European Prospective Osteoporosis Study (EPOS). J Bone Miner Res. 2002; 17(4):716-724. [PubMed: 11918229]

21. O'Neill TW, Felsenberg D, Varlow J, et al. The prevalence of vertebral deformity in european men and women: the European Vertebral Osteoporosis Study. J Bone Miner Res. 1996; 11(7):10101018. [PubMed: 8797123]

22. Davies KM, Stegman MR, Heaney RP, et al. Prevalence and severity of vertebral fracture: the Saunders County Bone Quality Study. Osteoporos Int. 1996; 6(2):160-165. [PubMed: 8704356]

23. Santavirta S, Konttinen YT, Heliovaara M, et al. Determinants of osteoporotic thoracic vertebral fracture. Screening of 57,000 Finnish women and men. Acta Orthop Scand. 1992; 63(2):198-202. [PubMed: 1590058]

24. Szulc P, Munoz F, Marchand F, et al. Semiquantitative evaluation of prevalent vertebral deformities in men and their relationship with osteoporosis: the MINOS study. Osteoporos Int. 2001; 12(4):302-310. [PubMed: 11420780]

25. Melton LJ 3rd, Atkinson EJ, Cooper C, et al. Vertebral fractures predict subsequent fractures. Osteoporos Int. 1999; 10(3):214-221. [PubMed: 10525713]

26. Hasserius R, Karlsson MK, Nilsson BE, et al. Prevalent vertebral deformities predict increased mortality and increased fracture rate in both men and women: a 10-year population-based study of 
598 individuals from the Swedish cohort in the European Vertebral Osteoporosis Study.

Osteoporos Int. 2003; 14(1):61-68. [PubMed: 12577186]

27. Burger H, Van Daele PL, Grashuis K, et al. Vertebral deformities and functional impairment in men and women. J Bone Miner Res. 1997; 12(1):152-157. [PubMed: 9240738]

28. Center JR, Bliuc D, Nguyen TV, et al. Risk of subsequent fracture after low-trauma fracture in men and women. JAMA. 2007; 297(4):387-394. [PubMed: 17244835]

29. Looker AC, Orwoll ES, Johnston CC Jr, et al. Prevalence of low femoral bone density in older U.S. adults from NHANES III. J Bone Miner Res. 1997; 12(11):1761-1768. [PubMed: 9383679]

30. Melton LJ 3rd, Atkinson EJ, O’Connor MK, et al. Bone density and fracture risk in men. J Bone Miner Res. 1998; 13(12):1915-1923. [PubMed: 9844110]

31. Khosla S. Update in male osteoporosis. J Clin Endocrinol Metab. 2010; 95(1):3-10. [PubMed: 20056806]

32. Kanis JA, Bianchi G, Bilezikian JP, et al. Towards a diagnostic and therapeutic consensus in male osteoporosis. Osteoporos Int. 2011; 22(11):2789-2798. [PubMed: 21509585]

33. Silverman SL, Madison RE. Decreased incidence of hip fracture in Hispanics, Asians, and blacks: California Hospital Discharge Data. Am J Public Health. 1988; 78(11):1482-1483. [PubMed: 3177728]

34. Drake MT, Murad MH, Mauck KF, et al. Risk Factors for Low Bone Mass-Related Fractures in Men: A Systematic Review and Meta-Analysis. J Clin Endocrinol Metab. 2012

35. Riggs BL, Melton LJ 3rd, Robb RA, et al. Population-based study of age and sex differences in bone volumetric density, size, geometry, and structure at different skeletal sites. J Bone Miner Res. 2004; 19(12):1945-1954. [PubMed: 15537436]

36. Turner CH. Bone strength: current concepts. Ann N Y Acad Sci. 2006; 1068:429-446. [PubMed: 16831941]

37. Marshall LM, Lang TF, Lambert LC, et al. Dimensions and volumetric BMD of the proximal femur and their relation to age among older U.S. men. J Bone Miner Res. 2006; 21(8):1197-1206. [PubMed: 16869717]

38. Khosla S, Riggs BL, Atkinson EJ, et al. Effects of sex and age on bone microstructure at the ultradistal radius: a population-based noninvasive in vivo assessment. J Bone Miner Res. 2006; 21(1):124-131. [PubMed: 16355281]

39. Silva MJ, Gibson LJ. Modeling the mechanical behavior of vertebral trabecular bone: effects of age-related changes in microstructure. Bone. 1997; 21(2):191-199. [PubMed: 9267695]

40. Khosla S, Melton LJ 3rd, Atkinson EJ, et al. Relationship of serum sex steroid levels and bone turnover markers with bone mineral density in men and women: a key role for bioavailable estrogen. J Clin Endocrinol Metab. 1998; 83(7):2266-2274. [PubMed: 9661593]

41. Slemenda CW, Longcope C, Zhou L, et al. Sex steroids and bone mass in older men. Positive associations with serum estrogens and negative associations with androgens. J Clin Invest. 1997; 100(7):1755-1759. [PubMed: 9312174]

42. Greendale GA, Edelstein S, Barrett-Connor E. Endogenous sex steroids and bone mineral density in older women and men: the Rancho Bernardo Study. J Bone Miner Res. 1997; 12(11):18331843. [PubMed: 9383688]

43. Center JR, Nguyen TV, Sambrook PN, et al. Hormonal and biochemical parameters in the determination of osteoporosis in elderly men. J Clin Endocrinol Metab. 1999; 84(10):3626-3635. [PubMed: 10523006]

44. van den Beld AW, de Jong FH, Grobbee DE, et al. Measures of bioavailable serum testosterone and estradiol and their relationships with muscle strength, bone density, and body composition in elderly men. J Clin Endocrinol Metab. 2000; 85(9):3276-3282. [PubMed: 10999822]

45. Amin S, Zhang Y, Sawin CT, et al. Association of hypogonadism and estradiol levels with bone mineral density in elderly men from the Framingham study. Ann Intern Med. 2000; 133(12):951963. [PubMed: 11119396]

46. Szulc P, Munoz F, Claustrat B, et al. Bioavailable estradiol may be an important determinant of osteoporosis in men: the MINOS study. J Clin Endocrinol Metab. 2001; 86(1):192-199. [PubMed: 11232000] 
47. Khosla S, Melton LJ 3rd, Atkinson EJ, et al. Relationship of serum sex steroid levels to longitudinal changes in bone density in young versus elderly men. J Clin Endocrinol Metab. 2001; 86(8):3555-3561. [PubMed: 11502778]

48. Khosla S, Riggs BL, Robb RA, et al. Relationship of volumetric bone density and structural parameters at different skeletal sites to sex steroid levels in women. J Clin Endocrinol Metab. 2005; 90(9):5096-5103. [PubMed: 15998772]

49. Gennari L, Merlotti D, Martini G, et al. Longitudinal association between sex hormone levels, bone loss, and bone turnover in elderly men. J Clin Endocrinol Metab. 2003; 88(11):5327-5333. [PubMed: 14602769]

50. Mellstrom D, Vandenput L, Mallmin H, et al. Older men with low serum estradiol and high serum SHBG have an increased risk of fractures. J Bone Miner Res. 2008; 23(10):1552-1560. [PubMed: 18518773]

51. Khosla S, Melton LJ 3rd, Riggs BL. The unitary model for estrogen deficiency and the pathogenesis of osteoporosis: is a revision needed? J Bone Miner Res. 2011; 26(3):441-451. [PubMed: 20928874]

52. Falahati-Nini A, Riggs BL, Atkinson EJ, et al. Relative contributions of testosterone and estrogen in regulating bone resorption and formation in normal elderly men. J Clin Invest. 2000; 106(12): 1553-1560. [PubMed: 11120762]

53. Nair KS, Rizza RA, O'Brien P, et al. DHEA in elderly women and DHEA or testosterone in elderly men. N Engl J Med. 2006; 355(16):1647-1659. [PubMed: 17050889]

54. Wakley GK, Schutte HD Jr, Hannon KS, et al. Androgen treatment prevents loss of cancellous bone in the orchidectomized rat. J Bone Miner Res. 1991; 6(4):325-330. [PubMed: 1858518]

55. Sattin RW, Lambert Huber DA, DeVito CA, et al. The incidence of fall injury events among the elderly in a defined population. Am J Epidemiol. 1990; 131(6):1028-1037. [PubMed: 2343855]

56. Paspati I, Galanos A, Lyritis GP. Hip fracture epidemiology in Greece during 1977-1992. Calcif Tissue Int. 1998; 62(6):542-547. [PubMed: 9576984]

57. Stevens JA, Sogolow ED. Gender differences for non-fatal unintentional fall related injuries among older adults. Inj Prev. 2005; 11(2):115-119. [PubMed: 15805442]

58. Kennel KA, Riggs BL, Achenbach SJ, et al. Role of parathyroid hormone in mediating age-related changes in bone resorption in men. Osteoporos Int. 2003; 14(8):631-636. [PubMed: 12851746]

59. Boonen S, Mohan S, Dequeker J, et al. Down-regulation of the serum stimulatory components of the insulin-like growth factor (IGF) system (IGF-I, IGF-II, IGF binding protein [BP]-3, and IGFBP-5) in age-related (type II) femoral neck osteoporosis. J Bone Miner Res. 1999; 14(12): 2150-2158. [PubMed: 10620075]

60. Undale AH, Westendorf JJ, Yaszemski MJ, et al. Mesenchymal stem cells for bone repair and metabolic bone diseases. Mayo Clin Proc. 2009; 84(10):893-902. [PubMed: 19797778]

61. Orwoll E, Ettinger M, Weiss S, et al. Alendronate for the treatment of osteoporosis in men. N Engl J Med. 2000; 343(9):604-610. [PubMed: 10979796]

62. Ringe JD, Faber H, Farahmand P, et al. Efficacy of risedronate in men with primary and secondary osteoporosis: results of a 1-year study. Rheumatol Int. 2006; 26(5):427-431. [PubMed: 16001181]

63. Orwoll ES, Binkley NC, Lewiecki EM, et al. Efficacy and safety of monthly ibandronate in men with low bone density. Bone. 2010; 46(4):970-976. [PubMed: 20060082]

64. Orwoll ES, Miller PD, Adachi JD, et al. Efficacy and safety of a once-yearly i.v. Infusion of zoledronic acid $5 \mathrm{mg}$ versus a once-weekly 70-mg oral alendronate in the treatment of male osteoporosis: a randomized, multicenter, double-blind, active-controlled study. J Bone Miner Res. 2010; 25(10):2239-2250. [PubMed: 20499357]

65. Sambrook PN, Roux C, Devogelaer JP, et al. Bisphosphonates and glucocorticoid osteoporosis in men: results of a randomized controlled trial comparing zoledronic acid with risedronate. Bone. 2012; 50(1):289-295. [PubMed: 22061864]

66. Bauman WA, Wecht JM, Kirshblum S, et al. Effect of pamidronate administration on bone in patients with acute spinal cord injury. J Rehabil Res Dev. 2005; 42(3):305-313. [PubMed: 16187243]

67. Girotra M, Rubin MR, Bilezikian JP. The use of parathyroid hormone in the treatment of osteoporosis. Rev Endocr Metab Disord. 2006; 7(1-2):113-121. [PubMed: 17043762] 
68. Murad MH, Drake MT, Mullan RJ, et al. Comparative Effectiveness of Drug Treatments to Prevent Fragility Fractures: A Systematic Review and Network Meta-Analysis. J Clin Endocrinol Metab. 2012

69. Dawson-Hughes B, Harris SS, Krall EA, et al. Effect of calcium and vitamin D supplementation on bone density in men and women 65 years of age or older. N Engl J Med. 1997; 337(10):670-676. [PubMed: 9278463]

70. Ross AC, Manson JE, Abrams SA, et al. The 2011 report on dietary reference intakes for calcium and vitamin D from the Institute of Medicine: what clinicians need to know. J Clin Endocrinol Metab. 2011; 96(1):53-58. [PubMed: 21118827]

71. Rosen CJ, Gallagher JC. The 2011 IOM report on vitamin D and calcium requirements for north america: clinical implications for providers treating patients with low bone mineral density. J Clin Densitom. 2011; 14(2):79-84. [PubMed: 21787514] 


\section{Key Points}

- In men, hip fractures are associated with the greatest morbidity and mortality

- Fracture incidence in males has two peaks: one around adolescence and a second, sustained peak which occurs at advanced age

- Morbidity is also increased in men compared to women following hip fracture; nearly half of men require skilled institutionalized care following hip fracture ${ }^{16}$, and men are far less likely when compared to women to return to full independence at one year following hip fracture ${ }^{17}$. 

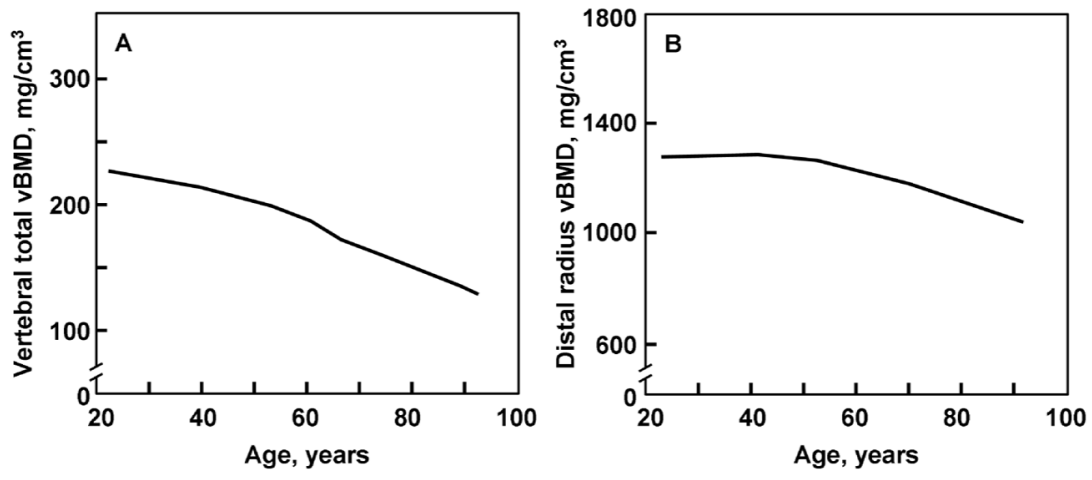

Figure 1.

A. Total vertebral body vBMD values $\left(\mathrm{mg} / \mathrm{cm}^{3}\right)$ from a population sample $(\mathrm{n}=323)$ of Rochester, Minnesota men aged 20-97 years. B. Cortical vBMD values at the distal radius in the same male cohort. Adapted from Riggs et al. (2004) J Bone Miner Res. 19:1945-1954 with permission from the American Society of Bone and Mineral Research. 


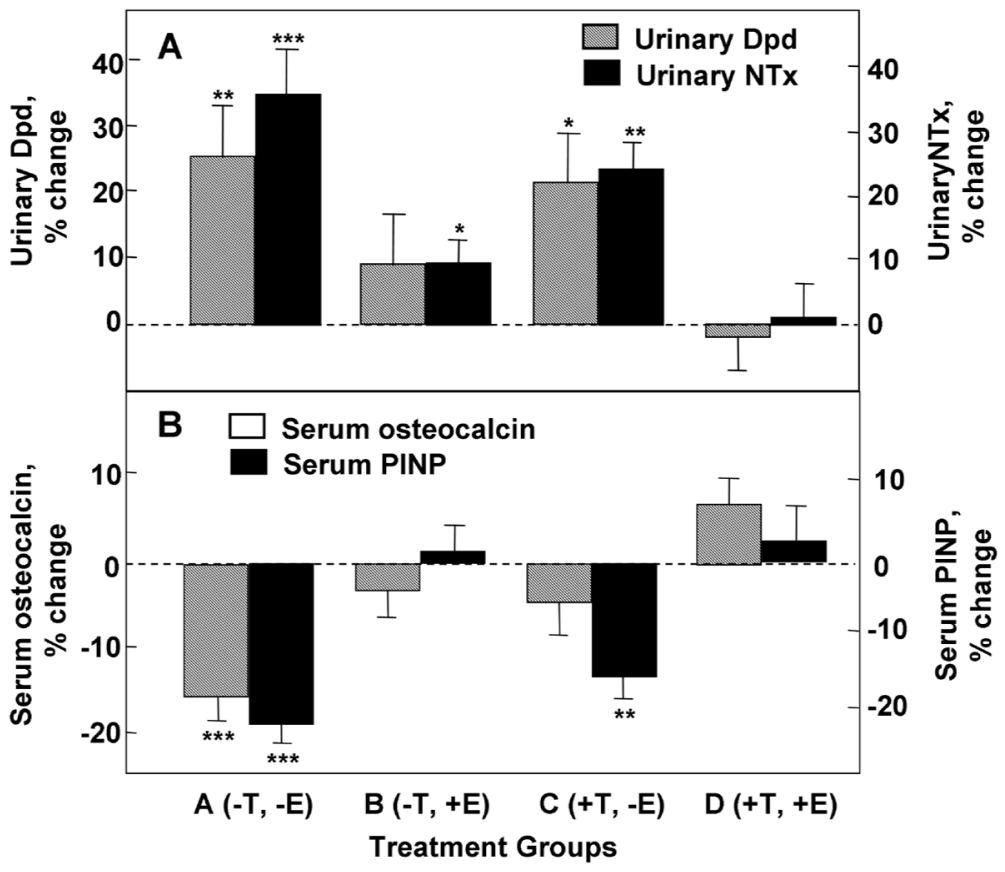

Figure 2.

Percent changes in markers of (A) bone resorption (urinary deoxypyridinoline [Dpd] and Ntelopeptide of type I collagen [NTX] and (B) bone formation (serum osteocalcin and Nterminal extension peptide of type I collagen [P1NP]) in elderly men (mean age, 68 years) pharmacologically made acutely hypogonadal and subsequently treated with either an aromatase inhibitor (group A), estrogen alone (group B), testosterone alone (group C), or both estrogen and testosterone (group D). Significance for change from baseline: ${ }^{*}, \mathrm{p}<0.05$; $* *, \mathrm{p}<0.01 ; * * *, \mathrm{p}<0.001$. Adapted from Falahati-Nini et al. (2000) J Clin Invest 106:1553-1560 with permission from the American Society for Clinical Investigation. 